J Racial Ethn Health Disparities. 2019 June ; 6(3): 517-524. doi:10.1007/s40615-018-00550-z.

\title{
Association Between Health Literacy and Medication Adherence among Hispanics With Hypertension
}

\author{
Maichou Lor, PhD RN ${ }^{1}$, Theresa A. Koleck, PhD, RN ${ }^{1}$, Suzanne Bakken, PhD, RN, FAAN, \\ FACMI $^{1,2,3}$, Sunmoo Yoon, PhD, RN ${ }^{1}$, and Ann Margaret Navarra, PhD, RN ${ }^{4}$ \\ ${ }^{1}$ Columbia University, School of Nursing \\ ${ }^{2}$ Columbia University, Biomedical Informatics \\ ${ }^{3}$ Columbia University, Data Science Institute \\ ${ }^{4}$ New York University, Rory Meyers College of Nursing
}

\section{Abstract}

Background: Poor adherence to prescribed antihypertensive medication is a major contributor to disparities in effective blood pressure control among Hispanics. The purpose of this study was to investigate the association between health literacy level and adherence to antihypertensive medications among Hispanic adults, who self-reported hypertension, controlling for potential covariates of adherence and/or health literacy.

Methods: We conducted a cross-sectional survey of 1,355 Hispanic adults, primarily Dominicans, who self-reported hypertension. Antihypertensive medication adherence and health literacy were evaluated along with covariates including sociodemographic characteristics, depression, anxiety, and sleep disturbance. Linear regression models were created for health literacy, each covariate, and adherence. Factors found to be significantly associated with adherence in the individual regression models at a p-value of $<0.20$ were included in a hierarchical multiple linear regression model.

Results: Overall, the majority of participants had low adherence levels to antihypertensive medications $(88.4 \% ; \mathrm{n}=1,026)$ and inadequate health literacy $(84.9 \% ; \mathrm{n}=1,151)$. When controlling for age, sex, birth country, education level, recruitment location, depression, anxiety, and sleep disturbance, having adequate as compared to inadequate health literacy was associated with a higher adherence score $(b=0.378, p=0.043)$. The full model explained $13.6 \%$ of the variance in

Corresponding author: Ann-Margaret Navarra, NYU Meyers College of Nursing, 433 First Avenue, NY, NY 10010, amd363@nyu.edu, 212-998-9009.

Conflict of Interest

All authors declare that they do not have any conflicts of interest.

Ethical Approval

The study received IRB approval from the Columbia University Medical Center's Institutional Review Board. All procedures performed in studies involving human participants were in accordance with the ethical standards of the institutional and/or national research committee and with the 1964 Helsinki declaration and its later amendments or comparable ethical standards.

Informed Consent

Informed consent was obtained from all participants included in the study.

Animal Studies

No animal studies were carried out by the authors for this article. 
medication adherence ( $\mathrm{p}$-value $<0.001$ ), but the unique contribution of health literacy to the model was minimal $\left(\mathrm{R}^{2}\right.$ change $\left.=0.003\right)$.

Conclusions.-Tailored interventions considering health literacy are needed to support medication adherence in order to improve hypertension outcomes of Hispanics. Additional studies are needed to identify and prioritize factors in the development of targeted and effective adherence interventions for Hispanics with hypertension.

\section{Keywords}

medication adherence; hypertension; Dominicans; Hispanics; health literacy

\section{Background}

Hypertension (HTN) is a leading cause of cardiovascular disease (CVD) and preventable mortality affecting 75 million adults in the United States (US), and contributing to more than 360,000 deaths in 2013 [1]. CVD is the second leading cause of death for Hispanics, a group currently representing $17.8 \%$ of the US population [2] with an expected increase to $29 \%$ by 2060 [3], [4]. A significant contributor to CVD for Hispanics is hypertension [5], with overall low rates of poor control in comparison to white cohorts [6]. Additionally, racial ethnic disparities persist for both initial treatment and long-term management of HTN [7]. Poor adherence to prescribed antihypertensive medication is a major contributor to disparities in effective blood pressure control among racial ethnic minorities including Hispanic patients [8]. Yet there is a paucity of evidence addressing adherence behavior in the Hispanic population [9]. Moreover, the majority of studies reporting on cardiovascular disease for US Hispanics has primarily focused on Mexicans; however these data may not be relevant to other Hispanic ethnic groups [10] including Dominicans. Given the current demographic shift in the US and prevalence of CVD among the Hispanic population [4], there is a pressing need to better understand factors influencing medication adherence among ethnic minority Hispanic adults with HTN.

According to the 2017 guidelines for high blood pressure in adults by the American College of Cardiology [11], maintaining optimal blood pressure control and treatment with blood pressure lowering agents or antihypertensives is imperative. Adherence of $80 \%$ or better to prescribed antihypertensive medications is an essential component of maintaining optimal blood pressure control $[12,13]$. The World Health Organization defines adherence to longterm therapy as the extent to which a person's behavior corresponds with agreed recommendations from a health care provider [14]. In general, levels of adherence to medications for chronic illness including CVD are estimated to be at 50\% [13,15] with half of patients discontinuing antihypertensive medications within one year of initiation [16].

Hispanics are less likely to be currently taking medications to control their blood pressure compared to non-Hispanic whites $[17,18]$. In fact, low levels of high medication adherence, defined as a score of eight on the Morrisky Adherence Scale have been reported in an urban, community dwelling cohort of US Hispanics, primarily of Dominican origin [19]. 
Patient adherence to antihypertensive treatment is influenced by a myriad of factors including sociodemographic characteristics (e.g., age, sex, education level, health insurance; [19,20], symptoms (e.g., depression, anxiety; [21,22], sleep [23]), and health literacy $[24,25]$, Health literacy refers to an individual's skills to gain access to, understand, and use information in ways that promote and maintain his or her health [26]. A systematic review of 35 studies revealed that there is a significant and positive relationship between health literacy and medication adherence [27]. Despite the reported findings, these factors are understudied in urban, Dominican Hispanic populations.

Therefore, the purpose of this study was to investigate the association between health literacy level and adherence to antihypertensive medications among Hispanic adults, who self-reported HTN, controlling for potential covariates/confounders of adherence, including demographic characteristics (i.e., age, sex, birth country, marital status, health insurance, education level, and recruitment location), and symptoms of depression, anxiety, and sleep disturbance.

\section{METHODS}

This study is part of a larger parent project, the Washington Heights/Inwood Informatics Infrastructure for Comparative Effectiveness Research (WICER) study [28-31]. The overall goal of the WICER study was to build a community-focused data infrastructure focused on improving the health of a Hispanic immigrant community at risk for health disparities. The WICER study was approved by the Columbia University Medical Center's Institutional Review Board.

\section{Setting and Participants}

A convenience sample was recruited between 2012 and 2013 from two distinct community settings representing five zip codes $(10031,10032,10033,10034$, and 10040) within the Washington Heights/Inwood communities of Northern Manhattan: 1) community households (HH) and 2) ambulatory care clinics (ACN) affiliated with New York Presbyterian Hospital. Eligible participants for the current analysis were 18 years or older, English or Spanish speaking, Hispanic, and self-reporting HTN.

\section{Recruitment and Data Collection}

Trained bilingual community health workers from the neighborhood recruited eligible participants. Multiple recruitment strategies were employed. The HH sample was recruited by probability sampling within the five target zip codes through ringing doorbells in the apartment buildings followed with snowball sampling. The ACN sample was recruited by inviting patients waiting for medical appointments in the ambulatory clinics to participate in the study. Participants completed the informed consent and the WICER Community Health Survey (CHS) in their preferred language (English or Spanish) using validated measures in either English and Spanish [32,33]. All participants completing the WICER CHS were compensated for their time and received a choice of two movie tickets, a \$25.00 New York City transit metro-card, or a $\$ 25.00$ food voucher to a local grocery store. 


\section{Community Health Survey (CHS)}

The WICER CHS collected comprehensive sociocultural information including demographic and health information as well as anthropometric measures from participants. Approximate time for completion of the survey was 60 to 120 minutes. Measures for the analysis were selected based on published literature.

\section{Measures}

Sociodemographic characteristics._Age, sex, birth country, marital status, health insurance, and education level were collected. Birth country was coded into three categories: (1) Dominican Republic, (2) United States, and (3) other countries. Marital status was dichotomized as partnered or not partnered. Not partnered individuals were those who indicated that they were widowed, single, separated, or divorced. Health insurance was dichotomized based on having Medicaid/Medicare or other. Education level was coded into three categories: completed (1) less than high school, (2) high school, and (3) some college or beyond.

Health literacy.-Health literacy was measured using the Newest Vital Sign (NVS), a rapid screening measure of adult health literacy in primary health care settings [34]. The NVS is a nutrition label and includes six questions, requiring three minutes for administration. Scores of 0-1 indicate high likelihood of limited literacy, scores of 2-3 suggest the possibility of limited literacy, and scores of $\geq 4$ are consistent with adequate literacy [34]. Psychometric testing of the NVS demonstrates reliability for both the English (Cronbach's $a>0.76$ ) and Spanish (Cronbach's $a=0.69$ ) versions [34]. Scores were recoded into a dichotomous variable of not adequate literacy (score of $\leq 3$ ) and adequate literacy (score of 24 ) level.

Symptom Status.-Depression was measured using the Patient-Reported Outcome Measurement Information System (PROMIS) Short Form v1.0 - Depression 4a [35]. The four-items ask, "In the past 7 days, I felt (1) worthless; (2) helpless; (3) depressed; and (4) hopeless" with responses of "never," "rarely", "sometimes," "often", or "always." Anxiety was measured with the PROMIS Short Form v1.0 - Emotional Distress-Anxiety 4a [35]. The four-items ask, "In the past 7 days, (1) I felt fearful; (2) I found it hard to focus on anything other than my anxiety, (3) my worries overwhelmed me, and (4) I felt uneasy" with responses of "never," "rarely", "sometimes," "often", or "always." Sleep was measured with the PROMIS Short Form v1.0 - Sleep Disturbance 4a [36]. The first item asks, "In the past 7 days, my sleep quality was" with responses of "very poor," "poor," "fair," "good," or "very good." The remaining three items ask, "In the past 7 days, (1) my sleep was refreshing, (2) I had a problem with my sleep, and (3) I had difficulty falling asleep" with responses "not at all," "a little bit," "somewhat," "quite a bit", or "very much." Reponses to the PROMIS measures for depression, anxiety, and sleep were summed and converted into a T-score metric with a mean of 50 (SD 10). Higher T-scores indicate more of the concept being measured (e.g., higher levels of anxiety).

Adherence.-Adherence to anti-hypertensive medications was measured with an eightitem self-report scale using the Morisky Medication Adherence Scale [37]. This adherence 
measure is reliable (Cronbach's $a=0.83$ ) with good concurrent and predictive validity in low-income, minority patients with HTN, and is significantly associated with blood pressure control $(\mathrm{p}<0.05)$. The possible range of scores is 0 to 8 . Scores of $\mathbf{5}$ indicate low adherence, scores of 6 to 7 indicate medium adherence, and scores of 8 indicate high adherence [37]. The total score was used as the dependent variable in the analysis.

\section{Statistical Analysis}

Data was imported into IBM SPSS Statistics, version 21 (Chicago, IL). Initially, we computed descriptive statistics (mean and standard deviation, median and range, frequency and percentage) to summarize demographic characteristics, adherence estimates, and health literacy scores. Data was assessed for normality. Bivariate correlations between each of the predictors and adherence were initially calculated. Unadjusted linear regression models with adherence as the outcomes were then created for each of the following predictor variables: health literacy, demographics (i.e., age, sex, birth country, marital status, health insurance, education level, recruitment locations), and symptoms (depression, anxiety, and sleep disturbance). Variables found to be significantly associated with adherence in the individual regression models at a p-value of $<0.20$ were then included in a hierarchical multiple linear regression model. The unique contribution of health literacy level in explaining the variance in medication adherence scores was evaluated in the final block of the hierarchical multiple linear regression model, adjusted for covariates/confounders meeting the $<0.20 \mathrm{p}$-value cutoff.

\section{RESULTS}

A total of 1,355 participants were included. Participants had a mean age of 62 (SD 11.05). Seventy-six percent were females, $68 \%$ did not have a partner, $90 \%$ were born in the Dominican Republic, $68.3 \%$ have less than a high school education, and $86.3 \%$ have Medicaid/Medicare (Table 1). We found that $84.9 \%(\mathrm{n}=1,151)$ of participants had inadequate health literacy. Adherence scores as measured by the Morisky Medication Adherence Scale ranged from 0 to 8 with a mean score of $1.94(\mathrm{SD}=2.15)$.

Table 2 shows the association of health literacy level, as well as each of the included covariates with adherence. Adequate health literacy was associated with a higher adherence score, i.e., "better" adherence ( $b=0.572$, $\mathrm{p}$-value $\left.=0.002, \mathrm{R}^{2}=0.008\right)$, as compared to inadequate health literacy levels. Age (p-value $=0.003)$, sex $(\mathrm{p}$-value $=0.017)$, education level ( $\mathrm{p}$-value $=0.002)$, birth country $(\mathrm{p}$-value $=0.070)$, recruitment location ( $\mathrm{p}$-value $=0.007)$, anxiety (p-value $<0.001$ ), depression (p-value $<0.001$ ), and sleep disturbance ( $\mathrm{p}$-value $<0.001$ ) met the $\mathrm{p}$-value $<0.20$ cutoff for inclusion in the full multiple linear regression model.

The full model was significant overall (p-value $<0.001$ ) with an $\mathrm{R}^{2}$ of 0.136 (Table 3 ). In the comparison of adequate to inadequate health literacy levels, adequate health literacy was associated with a higher adherence score, i.e., "better" adherence ( $b=0.378, p=0.043)$, when controlling for age, sex, birth country, education level, recruitment location, anxiety, depression, and sleep disturbance. However, the unique contribution of health literacy level to the model consisting of the covariates/confounders alone was minimal, $\mathrm{R}^{2}$ change $=0.003$. 
In addition, we found that as age increases, adherence scores decrease $(b=-0.015, p$ value $=0.013)$ and as anxiety $(b=0.036, p$-value $=0.001)$, depression $(0.029$, $p$-value $=0.024)$, and sleep disturbance $(b=0.058, p$-value $<0.001)$ increase, adherence scores increase. Male compared to female sex $(b=0.354$, $p$-value $=0.015)$ and being recruited from $\mathrm{ACN}$ compared to $\mathrm{HH}$ ( $\mathrm{b}=0.814$, $\mathrm{p}$-value $<0.001)$ were associated with higher adherence scores. High school $(b=-0.555, p$-value $=0.001)$ or some college education and beyond $(b=-0.512, p-$ value $=0.007$ ) was associated with lower adherence scores, compared to having less than a high school education. Likewise, compared to being born in the Dominican Republic, being born in the United States $(b=-0.031, p$-value $=0.935)$ or other countries $(b=-0.383$, $p$ value $=0.115$ ) was associated with lower adherence scores.

\section{DISCUSSION}

The findings from this study are among the first to describe the association between health literacy levels and HTN medication adherence among Hispanic adults, primarily Dominicans, who self-reported HTN, controlling for potential covariates of adherence and/or health literacy, including demographic characteristics, depression, anxiety, and sleep disturbance. Overall, the majority of participants had low adherence to antihypertensive medications (88.4\%) and inadequate health literacy (84.9\%). The results of this study demonstrate that when controlling for individually significant covariates, only $0.3 \%$ of the variation in medication adherence is explained by health literacy level as measured by the NVS. One possible explanation for this finding could be the lack of variability in health literacy levels among the study participants. Additionally, the NVS primarily assesses numeracy and requires mathematical skills to answer questions correctly [38] and results may have differed if another health literacy measure was used. However, the large number of participants in our study with inadequate health literacy is congruent with existing research that shows that racial ethnic minorities are far more likely to be at or below basic levels in health literacy skills [39]. Consistent with existing research, having adequate health literacy was associated with better adherence [27]. Consequently, more interventions are needed for low health literate populations in order to increase medication adherence. For example, researchers could develop tailored medication interventions that include aids to reinforce written information, personalize information, ease navigation and improve accessibility. A systematic review of 47 intervention studies revealed that such tailoring was both effective and strongly preferred by low health literate patients to help improve their medication adherence [40].

We also found that as age increases, adherence score decreases, indicating poor adherence to antihypertensive medications among Hispanic participants. This finding is contrary to research that has reported that younger age (e.g., aged 18-44 years [41]; < 60 [42]; <65 years [43])was associated with greater odds of non-adherence [41-43]. Declining cognitive status in older adults may contribute to poor adherence [44-47], but this was not explicitly measured in the WICER CHS.

Also inconsistent with existing research [19,20], we found that having completed high school or some college and beyond were associated with lower adherence scores compared to high school or less. Similarly, we found that as levels of anxiety, depression, and sleep 
disturbance increased, adherence also increased. This finding is inconsistent with results of previous research studies [21-23,41], and may explained by the limited variability in adherence scores among study participants and symptom scores that were slightly below the mean for the PROMIS measures reference population.

Among this study sample, male sex and recruitment from an ambulatory care practice (i.e., $\mathrm{ACN}$ ) were associated with better adherence. This finding is consistent with research that has demonstrated that males have higher levels of medication adherence than women, including those who are Hispanics and other ethnic groups with HTN and other chronic diseases [48-50]. In addition, it is possible that participants who were recruited from ACN have better adherence to antihypertensive medications because they may have more frequent contact with healthcare providers. Grigoryan, Pavlik, and Hyman (2012) found that higher adherence was seen in patients monitored by clinicians in the intervention clinics [51]. Despite such findings, there are clear disparities between women and men related to medication adherence. Tailored interventions to support medication adherence for each sex should be considered in order to improve medication adherence and ultimately health outcomes. It has been documented that barriers to antihypertensive medication adherence differ according to sex [52]. For instance, the presence of depressive symptoms and patients' dissatisfaction with communication with their health care provider were identified as barriers to adherence in women but not men [52]. Hence, interventions could address such barriers to increase medication adherence among women.

The strengths and weakness of the current study should be considered in the interpretation of the results. First, this study considered many important variables related to medication adherence. However, not all known covariates of adherence were assessed or included (e.g., income, social support, HTN beliefs and knowledge, and cognitive status, etc.). Future studies could investigate how such variables impact medication adherence among Hispanics. Second, our measures were self-reported and response bias may be present. However, all interviewers were trained to reduce bias. Third, there was limited variability in health literacy, and medication adherence measures. Despite these limitations, major strengths of the current study include the use of a relatively large sample size of Hispanic participants who were mainly Dominican, and the use of validated and conventional measures for health literacy and medication adherence [53].

\section{CONCLUSION}

This study is one of the first to examine the association between health literacy and antihypertensive medication adherence among a large sample of Hispanics, primarily Dominicans, who self-reported HTN. Higher health literacy was found to be associated with better adherence. However, both health literacy and self-reported antihypertensive medication adherence levels were low in the majority of study participants. In addition, being male and recruited from an ambulatory care practice were associated with better adherence. Hence, future intervention could be tailored to reflect sex differences and consider care settings to improve antihypertensive medication adherence among Hispanics. Moving forward, an important research priority is the need for studies designed to identify 
and prioritize factors in the development of tailored and effective adherence interventions for Hispanics with HTN.

\section{Acknowledgements}

The Washington Heights/Inwood Informatics Infrastructure for Comparative Effectiveness Research was supported by R01HS019853 and R01HS022961. The analysis and manuscript preparation were supported by the Reducing Health Disparities Through Informatics training grant (T32NR007969) and the Precision in Symptom SelfManagement (PriSSM) Center (P30NR016587). Dr. Koleck is also supported by K99NR017651 and Dr. Navarra by K23 NR015970.

\section{REFERENCES}

1. Merai R CDC Grand Rounds: A Public Health Approach to Detect and Control Hypertension. MMWR Morb Mortal Wkly Rep. 2016;65:1261-4. [PubMed: 27855138]

2. United States Census Bureau. QuickFacts: UNITED STATES [Internet]. 2017 [cited 2018 Jun 1]. Available from: https://www.census.gov/quickfacts/fact/table/US/PST045217May 14th, 2018.

3. Colby SL, Ortman JM. Projections of the Size and Composition of the U.S: 2014-2060 [Internet], 2015 p. 1-13. Available from: https://census.gov/content/dam/Census/library/publications/2015/ demo/p25-1143.pdf May 14th, 2018.

4. Centers for Disease Control and Prevention, Office of Minority Health and Health Equity. Hispanic Health [Internet]. 2015 Available from: http://www.cdc.gov/vitalsigns/hispanic-health/index.html May 14th, 2018.

5. Sorlie PD, Allison MA, Avilés-Santa ML, Cai J, Daviglus ML, Howard AG, et al. Prevalence of hypertension, awareness, treatment, and control in the Hispanic Community Health Study/Study of Latinos. Am J Hypertens. 2014;27:793-800. [PubMed: 24627442]

6. Gu A, Yue Y, Desai RP, Argulian E. Racial and Ethnic Differences in Antihypertensive Medication Use and Blood Pressure Control Among US Adults With Hypertension: The National Health and Nutrition Examination Survey, 2003 to 2012. Circ Cardiovasc Qual Outcomes. 2017;10:2105-14.

7. Ferdinand KC, Nasser SA. Understanding the Importance of Race/Ethnicity in the Care of the Hypertensive Patient. Curr Hypertens Rep. 2015; 17:15. [PubMed: 25754318]

8. Poon I, Lai LS, Ford ME, Braun UK. Racial/ethnic disparities in medication use among veterans with hypertension and dementia: a national cohort study. Ann Pharmacother. 2009;43:185-93. [PubMed: 19193586]

9. Schoenthaler A, De La Calle F, Barrios-Barrios M, Garcia A, Pitaro M, Lum A, et al. A practicebased randomized controlled trial to improve medication adherence among Latinos with hypertension: study protocol for a randomized controlled trial. Trials. 2015;16:290. [PubMed: 26134837]

10. Rodriguez CJ, Allison M, Daviglus ML, Isasi CR, Keller C, Leira EC, et al. Status of cardiovascular disease and stroke in Hispanics/Latinos in the United States: a science advisory from the American Heart Association. Circulation. 2014;130:593-625. [PubMed: 25098323]

11. Whelton PK, Carey RM, Aronow WS, Casey DE, Collins KJ, Himmelfarb CD, et al. 2017 ACC/AHA/AAPA/ABC/ACPM/AGS/APhA/ASH/ASPC/NMA/PCNA Guideline for the Prevention, Detection, Evaluation, and Management of High Blood Pressure in Adults: A Report of the American College of Cardiology/American Heart Association Task Force on Clinical Practice Guidelines. Journal of the American College of Cardiology. 2018;71:el27-248.

12. Kronish IM, Leventhal H, Horowitz CR. Understanding minority patients' beliefs about hypertension to reduce gaps in communication between patients and clinicians. J Clin Hypertens (Greenwich). 2012;14:38-44. [PubMed: 22235822]

13. Ho PM, Bryson CL, Rumsfeld JS. Medication adherence: its importance in cardiovascular outcomes. Circulation. 2009;119:3028-35. [PubMed: 19528344]

14. World Health Organization. Adherence to Long-Term Therapies: Evidence for Action. Geneva, Switzerland: World Health Organization; 2003. 
15. Brown MT, Bussell JK. Medication adherence: WHO cares? Mayo Clin Proc. 2011;86:304-14. [PubMed: 21389250]

16. Vrijens B, Vincze G, Kristanto P, Urquhart J, Burnier M. Adherence to prescribed antihypertensive drug treatments: longitudinal study of electronically compiled dosing histories. BMJ. 2008;336:1114-7. [PubMed: 18480115]

17. Redmond N, Baer HJ, Hicks LS. Health behaviors and racial disparity in blood pressure control in the national health and nutrition examination survey. Hypertension. 2011;57:383-9. [PubMed: 21300667]

18. Sudano JJ, Baker DW. Antihypertensive medication use in Hispanic adults: a comparison with black adults and white adults. Med Care. 2001;39:575-87. [PubMed: 11414262]

19. Bandi P, Goldmann E, Parikh NS, Farsi P, Boden-Albala B. Age-Related Differences in Antihypertensive Medication Adherence in Hispanics: A Cross-Sectional Community-Based Survey in New York City, 2011-2012. Prev Chronic Dis. 2017;14:E57. [PubMed: 28704175]

20. Rolnick SJ, Pawloski PA, Hedblom BD, Asche SE, Bruzek RJ. Patient characteristics associated with medication adherence. Clin Med Res. 2013;11:54-65. [PubMed: 23580788]

21. Kretchy IA, Owusu-Daaku FT, Danquah SA. Mental health in hypertension: assessing symptoms of anxiety, depression and stress on anti-hypertensive medication adherence. Int J Ment Health Syst. 2014;8:25-31. [PubMed: 24987456]

22. Bautista LE, Vera-Cala LM, Colombo C, Smith P. Symptoms of depression and anxiety and adherence to antihypertensive medication. Am J Hypertens. 2012;25:505-11. [PubMed: 22258334]

23. Phillips KD, Moneyham L, Murdaugh C, Boyd MR, Tavakoli A, Jackson K, et al. Sleep disturbance and depression as barriers to adherence. Clin Nurs Res. 2005;14:273-93. [PubMed: 15995155]

24. McNaughton CD, Jacobson TA, Kripalani S. Low literacy is associated with uncontrolled blood pressure in primary care patients with hypertension and heart disease. Patient Education and Counseling. 2014;96:165-70. [PubMed: 24882088]

25. Berkman ND, Sheridan SL, Donahue KE, Halpern DJ, Crotty K. Low Health Literacy and Health Outcomes: An Updated Systematic Review. Ann Intern Med. 2011; 155:97-107. [PubMed: 21768583]

26. Nutbeam D Health promotion glossary. Health Promot. 1986; 1:113-27. [PubMed: 10318625]

27. Zhang NJ, Terry A, McHorney CA. Impact of Health Literacy on Medication Adherence: A Systematic Review and Meta-analysis. Annals of Pharmacotherapy. 2014;48:741-51. [PubMed: 24619949]

28. Yoon S, Suero-Tejeda N, Bakken S A Data Mining Approach for Examining Predictors of Physical Activity Among Urban Older Adults. J Gerontol Nurs. 2015;41:14-20.

29. Lee YJ, Boden-Albala B, Jia H, Wilcox A, Bakken S. The Association Between Online Health Information-Seeking Behaviors and Health Behaviors Among Hispanics in New York City: A Community-Based Cross-Sectional Study. J Med Internet Res. 2015;17:e261. [PubMed: 26611438]

30. Masterson Creber RM, Fleck E, Liu J, Rothenberg G, Ryan B, Bakken S. Identifying the Complexity of Multiple Risk Factors for Obesity Among Urban Latinas. J Immigr Minor Health. 2017;19:275-84. [PubMed: 27225251]

31. Sepulveda-Pacsi AL, Bakken S. Correlates of Dominicans' Identification of Cancer as a Worrisome Health Problem. J Immigr Minor Health. 2017;19:1227-34. [PubMed: 27766506]

32. PROMIS Health Organization. PROMIS $®$ measures are available in languages other than English. [Internet]. [cited 20186 12]. Available from: http://www.healthmeasures.net/exploremeasurement-systems/promis/intro-to-promis/available-translations

33. Health Literacy Tool Shed. Newest Vital Sign Spanish Version - NVS-SP [Internet]. 2005 [cited 2018 Jun 12]. Available from: https://healthliteracy.bu.edu/nvs-sp

34. Weiss BD, Hart G, McGee DL, D'Estelle S. Health status of illiterate adults: relation between literacy and health status among persons with low literacy skills. J Am Board Fam Pract. 1992;5:257-64. [PubMed: 1580173] 
35. Pilkonis PA, Choi SW, Reise SP, Stover AM, Riley WT, Celia D, et al. Item banks for measuring emotional distress from the Patient-Reported Outcomes Measurement Information System

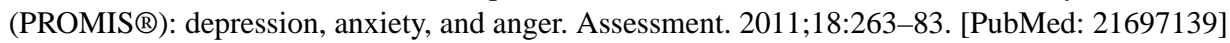

36. Yu L, Buysse DJ, Germain A, Moul DE, Stover A, Dodds NE, et al. Development of short forms from the PROMIS ${ }^{\mathrm{TM}}$ sleep disturbance and Sleep-Related Impairment item banks. Behav Sleep Med. 2011;10:6-24. [PubMed: 22250775]

37. Morisky DE, Ang A, Krousel-Wood M, Ward HJ. Predictive Validity of a Medication Adherence Measure in an Outpatient Setting. The Journal of Clinical Hypertension. 2008;10:348-354. [PubMed: 18453793]

38. Dunn-Navarra A-M, Stockwell MS, Meyer D, Larson E. Parental Health Literacy, Knowledge and Beliefs Regarding Upper Respiratory Infections (URI) in an Urban Latino Immigrant Population. J Urban Health. 2012;89:848-60. [PubMed: 22707307]

39. Institute of Medicine (US) Forum on the Science of Health Care Quality Improvement and Implementation, Institute of Medicine (US) Roundtable on Health Disparities, Institute of Medicine (US) Roundtable on Health Literacy. Toward Health Equity and Patient-Centeredness: Integrating Health Literacy, Disparities Reduction, and Quality Improvement: Workshop Summary [Internet]. Washington (DC): National Academies Press (US); 2009 [cited 2018 May 26]. Available from: http://www.ncbi.nlm.nih.gov/books/NBK37533/

40. Wali H, Hudani Z, Wali S, Mercer K, Grindrod K. A systematic review of interventions to improve medication information for low health literate populations. Research in Social and Administrative Pharmacy. 2016;12:830-64. [PubMed: 26926671]

41. Tong X, Chu EK, Fang J, Wall HK, Ayala C. Nonadherence to Antihypertensive Medication Among Hypertensive Adults in the United States-HealthStyles, 2010. J Clin Hypertens (Greenwich). 2016;18:892-900. [PubMed: 26841710]

42. Lee GKY, Wang HHX, Liu KQL, Cheung Y, Morisky DE, Wong MCS. Determinants of medication adherence to antihypertensive medications among a Chinese population using Morisky Medication Adherence Scale. PLoS ONE. 2013;8:e62775. [PubMed: 23638143]

43. Kripalani S, Gatti ME, Jacobson TA. Association of age, health literacy, and medication management strategies with cardiovascular medication adherence. Patient Educ Couns. 2010;81:177-81. [PubMed: 20684870]

44. Insel K, Morrow D, Brewer B, Figueredo A. Executive function, working memory, and medication adherence among older adults. J Gerontol B Psychol Sci Soc Sci. 2006;61:P102-107. [PubMed: 16497953]

45. Levinthal BR, Morrow DG, Tu W, Wu J, Murray MD. Cognition and health literacy in patients with hypertension. J Gen Intern Med. 2008;23:1172-6. [PubMed: 18459011]

46. Gellad WF, Grenard JL, Marcum ZA. A systematic review of barriers to medication adherence in the elderly: looking beyond cost and regimen complexity. Am J Geriatr Pharmacother. 2011;9:1123. [PubMed: 21459305]

47. Vawter L, Tong X, Gemilyan M, Yoon PW. Barriers to antihypertensive medication adherence among adults--United States, 2005. J Clin Hypertens (Greenwich). 2008;10:922-9. [PubMed: 19120718]

48. Chen S-L, Lee W-L, Liang T, Liao I-C. Factors associated with gender differences in medication adherence: a longitudinal study. J Adv Nurs. 2014;70:2031-40. [PubMed: 24506542]

49. Granger BB, Ekman I, Granger CB, Ostergren J, Olofsson B, Michelson E, et al. Adherence to medication according to sex and age in the CHARM programme. Eur J Heart Fail. 2009;11:10928. [PubMed: 19875409]

50. Li W-W, Wallhagen MI, Froelicher ES. Factors predicting blood pressure control in older Chinese immigrants to the United States of America. J Adv Nurs. 2010;66:2202-12. [PubMed: 20722800]

51. Grigoryan L, Pavlik VN, Hyman DJ. Predictors of antihypertensive medication adherence in two urban health-care systems. Am J Hypertens. 2012;25:735-8. [PubMed: 22441507]

52. Holt E, Joyce C, Domelles A, Morisky D, Webber LS, Muntner P, et al. Sex Differences in Barriers to Antihypertensive Medication Adherence: Findings From the Cohort Study of Medication Adherence Among Older Adults (CoSMO). J Am Geriatr Soc. 2013;61:558-64. [PubMed: 23528003] 
53. Manias E, Bucknall T, Botti M. Assessment of patient pain in the postoperative context. West J Nurs Res. 2004;26:751-69. [PubMed: 15466612] 


\section{Table 1}

Sample demographic characteristics $(\mathrm{N}=1,355)$

\begin{tabular}{|c|c|c|}
\hline Variable & Count & Percent \\
\hline \multicolumn{3}{|l|}{ Cohort } \\
\hline Ambulatory Care Clinics(ACN) & 1,112 & 82.1 \\
\hline Household (HH) & 243 & 17.9 \\
\hline \multicolumn{3}{|l|}{ Sex } \\
\hline Female & 1,030 & 76 \\
\hline Male & 325 & 24 \\
\hline \multicolumn{3}{|l|}{ Marital Status } \\
\hline Partnered & 433 & 32 \\
\hline Not Partnered & 922 & 68 \\
\hline \multicolumn{3}{|l|}{ Birth Country } \\
\hline United States & 41 & 3 \\
\hline Dominican Republic & 1,219 & 90 \\
\hline Other & 88 & 6.5 \\
\hline Missing & 7 & 0.5 \\
\hline \multicolumn{3}{|l|}{ Health Insurance } \\
\hline Medicaid/Medicare & 1,170 & 86.3 \\
\hline Other & 168 & 12.4 \\
\hline \multicolumn{3}{|l|}{ Education } \\
\hline Less than high school education & 926 & 68.3 \\
\hline High School & 235 & 17.3 \\
\hline Some college and beyond & 189 & 13.9 \\
\hline Missing & 5 & 0.4 \\
\hline \multicolumn{3}{|l|}{ Newest Vital Sign- limited literacy } \\
\hline Yes & 1,151 & 84.9 \\
\hline No & 188 & 13.9 \\
\hline \multirow[t]{2}{*}{ Missing } & 16 & 1.2 \\
\hline & Mean & SD \\
\hline Age & 62.27 & 11.05 \\
\hline Medication adherence sum & 1.94 & 2.15 \\
\hline Anxiety & 47.39 & 9.54 \\
\hline Depression & 46.51 & 8.01 \\
\hline Sleep disturbance & 49.94 & 4.98 \\
\hline
\end{tabular}

J Racial Ethn Health Disparities. Author manuscript; available in PMC 2020 June 01. 


\section{롤 \\ 일}

를

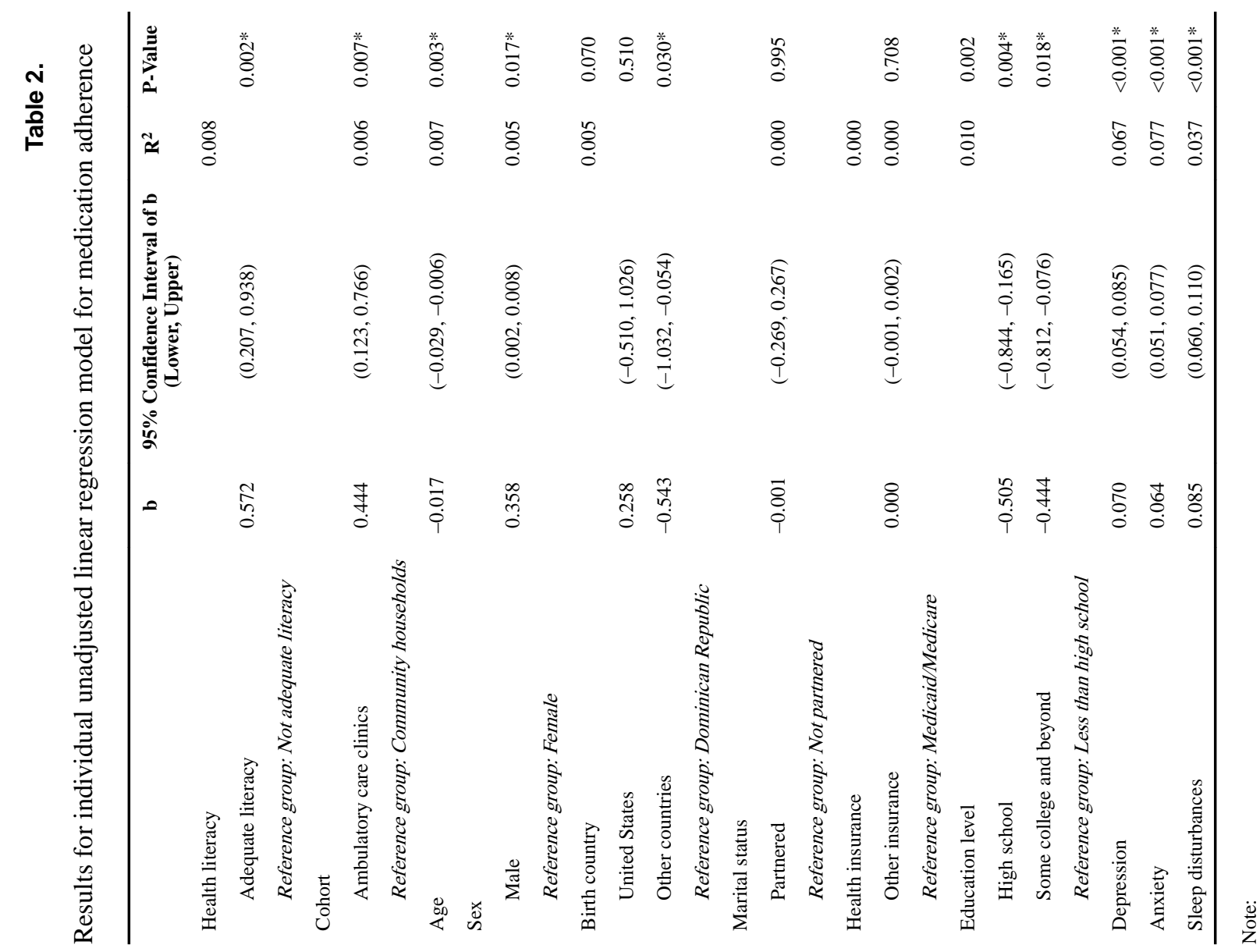

J Racial Ethn Health Disparities. Author manuscript; available in PMC 2020 June 01. 


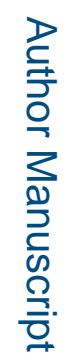

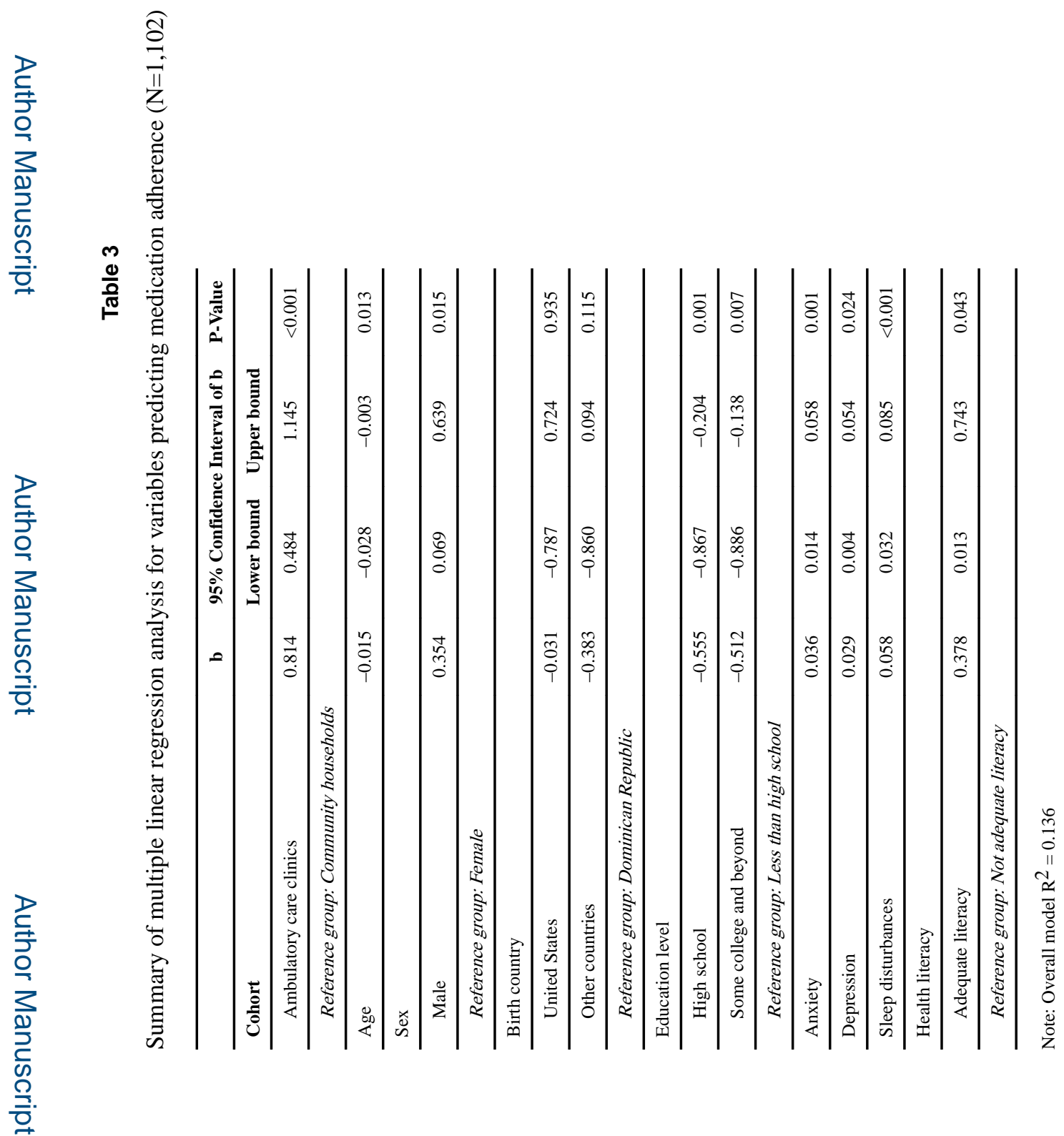

J Racial Ethn Health Disparities. Author manuscript; available in PMC 2020 June 01. 